\section{FedUni ResearchOnline}

\section{https://researchonline.federation.edu.au}

Copyright Notice

This is the peer-reviewed version of the following article:

Menon, M., et al. (2019). Decision Support Tools for Preventive Maintenance Intervals and Replacement Decisions of Engineering Assets. 2018 IEEE International Conference on Industrial Engineering and Engineering Management, IEEM 2018, IEEE Computer Society.

Which has been published in final form at:

https://doi.org/10.1109/IEEM.2018.8607601

Copyright (C 2018 IEEE. Personal use of this material is permitted. Permission from IEEE must be obtained for all other uses, in any current or future media, including reprinting/republishing this material for advertising or promotional purposes, creating new collective works, for resale or redistribution to servers or lists, or reuse of any copyrighted component of this work in other works. 


\title{
DECISION SUPPORT TOOLS FOR PREVENTIVE MAINTENANCE INTERVALS AND REPLACEMENT DECISIONS OF ENGINEERING ASSETS.
}

\author{
M. Menon ${ }^{1}$, G. Chattopadhyay ${ }^{2}$ and R. Beebe ${ }^{3}$ \\ ${ }^{1,2,3}$ School of Science Engineering \& Information Technology Federation University Australia, Churchill, Australia \\ (menon.km@gmail.com)
}

\begin{abstract}
Prognostic models for maintenance decisions have inherent limitations due to quality \& quantity of historical data, assumptions made, and time required in validating models. In this paper, Preventive Maintenance (PM) Intervals, Failure events, cost and maintenance records from Computerized Maintenance Management System (CMMS) are analyzed for reducing downtimes and Operating Expenditure (OPEX). The proposed methodologies for maintenance intervals and replacements with acceptable level of confidence are articulated to asset maintenance of a City Council of Australian Local Government organisation as a case of improved decision making under limited information.
\end{abstract}

Keywords - Decision Support, Preventive Maintenance Interval, Weibull Analysis, Risk Ranking, Degradation Modeling

\section{INTRODUCTION}

Asset management decisions have significant influence on operating and capital expenditure of any big organisation similar to city council. Illustrative example from Australian Local Government organisation is considered in this study for unstructured and at times insufficient field data resulting a risk based informed decision making in maintenance and replacement of engineering assets for reduced costs and risks along with enhanced performance.

Issues and challenges in wastewater treatment plants and sewer pressure mains of the city council assets are studied and analyzed in this research project. Failure modelling, non-destructive wall thickness assessment and parametric survival curves are proposed to better estimate capital investment needs and more accurate replacement timelines.

\section{METHODOLOGY}

Balancing Risk, Performance and Cost is now a globally accepted trend in good practice asset management in line with, ISO55000, ISO standard for asset management. This study is performed on two groups of assets where decisions are more influenced by cost in one set of assets and risks in the other set of assets.

In the evolution of maintenance strategy, the domain of traditional reliability engineering sits between Corrective Maintenance (CM) and Preventive Maintenance (PM) whereas Prognostics and Health Management (PHM) positions between PM and CM[1]. Prognostics is the key enabler that permits evaluation of system reliability by predicting failures more accurately and providing informed risk based decision making in maintenance of assets and capital expenditure. Prognostic modelling is able to better predict remaining useful life [2, $3]$. It is able to develop health management roadmap of assets through a general path model [4. 5]

Park, Tin and, Jeong proposed a framework for modelling the likelihood of failure of underground pipeline assets [6]. Chattopadhyay and Kumar estimated parameter for degradation using parametric modelling approach [7]. Chattopadhyay discussed issues and challenges of balancing cost, performance and risk in life cycle management of capital intensive assets [8]. Beebe extensively covered predictive maintenance of pumps using effective condition monitoring approach [9]. Rahman and Chattopadhyay proposed optimal service contract policies for outsourcing maintenance services [10]. Chattopadhyay and Yun developed 2D models and analyzed warranty costs for reducing risks of failures [11].

Techniques of fault diagnosis for Condition Based Maintenance (CBM) are more mature in research for life cycle management of industrial products/systems compared to that of PHM method, which has been significantly growing in recent years. International Standard ISO 13381-1 provides a comprehensive guidelines for performing failure prognostics of engineering systems [12]. Prognostics is defined as an estimation of time to failure and associated risks of one or more known and potential failure modes. A sound methodology is used for generating Weibull parameters of failure data and is applied in risk based decision making in maintenance.

Historical data available from City Council's CMMS was used for analysis and illustrative example of this paper.

\section{INSTRUMENT ASSETS}

Instrument assets of various types (asset classes) were considered from Waste Water Treatment Plants (WWTP) of the city council in Australia. Analysis showed that primary impacts of low and/ or non-availability of these instruments were increased costs, followed by reduced performance. Business risk resulting from failure of these assets was not significant.

Figure 1 shows that 14 out of 73 classes of assets contributed significant portion of total maintenance cost. Further distribution of cost for Reactive Maintenance (RM), Preventive Maintenance (PM) and Total 
Maintenance was analysed for broad objectives of asset management actions and is provided in Table 1.

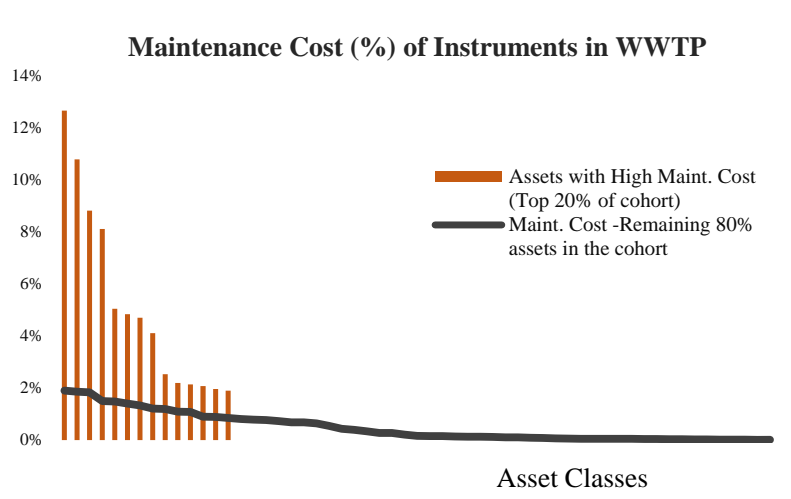

Fig. 1. Distribution of Maintenance cost among Instrument asset classes

TABLE 1

MAINTENANCE COST DISTRIBUTION AND OBJECTIVE

\begin{tabular}{|l|c|c|c|c|c|c|}
\hline \multicolumn{1}{|c|}{ Asset Class } & $\mathrm{RM}$ & $\mathrm{PM}$ & $\begin{array}{c}\text { Total } \\
\text { Cost }\end{array}$ & $\begin{array}{c}\mathrm{PM} / \\
\text { Total }\end{array}$ & $\begin{array}{c}\mathrm{RM} / \\
\text { Total }\end{array}$ & $\begin{array}{c}\text { Objecti } \\
\text { ve }\end{array}$ \\
\hline $\begin{array}{l}\text { Dissolved } \\
\text { Oxygen } \\
\text { Analyser }\end{array}$ & 3 & 2 & 1 & $52 \%$ & $45 \%$ & $\begin{array}{c}<\mathrm{PM}, \\
<\mathrm{RM}\end{array}$ \\
\hline Actuator & 1 & $\mathrm{~N}$ & 2 & $9 \%$ & $85 \%$ & $<\mathrm{RM}$ \\
\hline Flow Meter & 2 & 7 & 3 & $20 \%$ & $79 \%$ & $\begin{array}{c}<\mathrm{RM}, \\
<\mathrm{PM}\end{array}$ \\
\hline pH Meter & 9 & 1 & 4 & $82 \%$ & $16 \%$ & $\begin{array}{c}<\mathrm{PM}, \\
<\mathrm{RM}\end{array}$ \\
\hline $\begin{array}{l}\text { Level Sensing } \\
\text { Element }\end{array}$ & 4 & $\mathrm{~N}$ & 5 & $19 \%$ & $80 \%$ & $<\mathrm{RM}$ \\
\hline $\begin{array}{l}\text { Level } \\
\text { Transmitter }\end{array}$ & 5 & $\mathrm{~N}$ & 6 & $24 \%$ & $66 \%$ & $<\mathrm{RM}$ \\
\hline $\begin{array}{l}\text { Turbidity } \\
\text { Analyser }\end{array}$ & 6 & 9 & 7 & $28 \%$ & $68 \%$ & $\begin{array}{c}<\mathrm{RM}, \\
<\mathrm{PM}\end{array}$ \\
\hline $\begin{array}{l}\text { Solenoid } \\
\text { Valve }\end{array}$ & 7 & 8 & 8 & $42 \%$ & $57 \%$ & $\begin{array}{c}<\mathrm{RM}, \\
<\mathrm{PM}\end{array}$ \\
\hline $\begin{array}{l}\text { UV Intensity } \\
\text { Sensor }\end{array}$ & 11 & 11 & 9 & $47 \%$ & $46 \%$ & $\begin{array}{c}<\mathrm{PM}, \\
<\mathrm{RM}\end{array}$ \\
\hline $\begin{array}{l}\text { Pressure } \\
\text { Transmitter }\end{array}$ & 8 & $\mathrm{~N}$ & 10 & $35 \%$ & $65 \%$ & $<\mathrm{RM}$ \\
\hline $\begin{array}{l}\text { Nutrient } \\
\text { Analyser }\end{array}$ & $\mathrm{N}$ & 5 & 11 & $85 \%$ & $15 \%$ & $<\mathrm{PM}$ \\
\hline Flow Switch & $\mathrm{N}$ & 3 & 12 & $87 \%$ & $13 \%$ & $<\mathrm{PM}$ \\
\hline $\begin{array}{l}\text { Orthophospha } \\
\text { te Sensor }\end{array}$ & $\mathrm{N}$ & 6 & 13 & $92 \%$ & $8 \%$ & $<\mathrm{PM}$ \\
\hline $\begin{array}{l}\text { Chlorine } \\
\text { Residual } \\
\text { Analyser }\end{array}$ & $\mathrm{N}$ & 12 & 1 & $57 \%$ & $40 \%$ & $<\mathrm{PM}$ \\
\hline
\end{tabular}

Analysis is conducted based on relative costs for Reactive Maintenance, Preventive Maintenance and Total Maintenance Cost. Actions are classified into four categories or groups, as shown in Table 2.

TABLE 2

RANKING OF HIGH MAINTENANCE COST CLASSES

\begin{tabular}{|c|l|}
\hline Group & \multicolumn{1}{|c|}{ Action } \\
\hline 1 & Reduce cost of PM \\
\hline 2 & Prioritize PM cost reduction over RM cost \\
\hline 3 & Prioritize RM cost reduction over PM cost \\
\hline 4 & Reduce cost of RM \\
\hline
\end{tabular}

For each of the 14 instrument asset classes, Time to Failure (days), Frequency of PM and Cost of RM \& PM were analysed from CMMS data.

Recommendations from Original Equipment Manufacturer (OEM) on maintenance scope used to overrule any other considerations during initial years of operation of plant. As maintenance management system, personnel skills and asset knowledge matured, the asset owners looked for feasible opportunities for further improving decision making of maintenance schedules including capital investments. Key considerations were eliminating unnecessary PMs, incorporating lessons learnt from performance data and reducing OPEX, wherever possible, through rationalisation of PM.

A failure prediction model was proposed using Weibull analysis for asset class behavior. Each valid RM Work Order is counted as a failure event in this analysis using available data from 01-July-2013 to 27-Feb-2017. Time between two consecutive failure events (TBF) in this period is extracted for each asset of any particular asset class. Assets having identical functions, specification and similar failure modes are pooled together in this analysis.

\section{RESULTS FROM INSTRUMENT ASSETS}

A typical case of a Flow Meter is considered here for an illustrative example. As the range of TBF varied between 2 to 638 days for 38 failure events of Flow Meter, a normalized parameter $\mathrm{T}^{*}$ was used. This approach was taken due to unavailability of failure data prior to 01-July2013 .

$$
\begin{aligned}
& \mathrm{T} *=\mathrm{T}+\operatorname{Stdev}\left(\sum \mathrm{TBF}\right) \\
& \text { Median Rank }=\frac{(\mathrm{f}(\mathrm{i})-0.3)}{(\mathrm{f}(\mathrm{n})+0.4)}
\end{aligned}
$$

Weibull curve for Flow Meter was generated by plotting $\ln \left(\mathrm{T}^{*}\right)$ against $\ln \left(\ln \left(\frac{1}{(1-\text { Median Rank })}\right)\right.$. The resulting Weibull plot is provided in Figure 2.

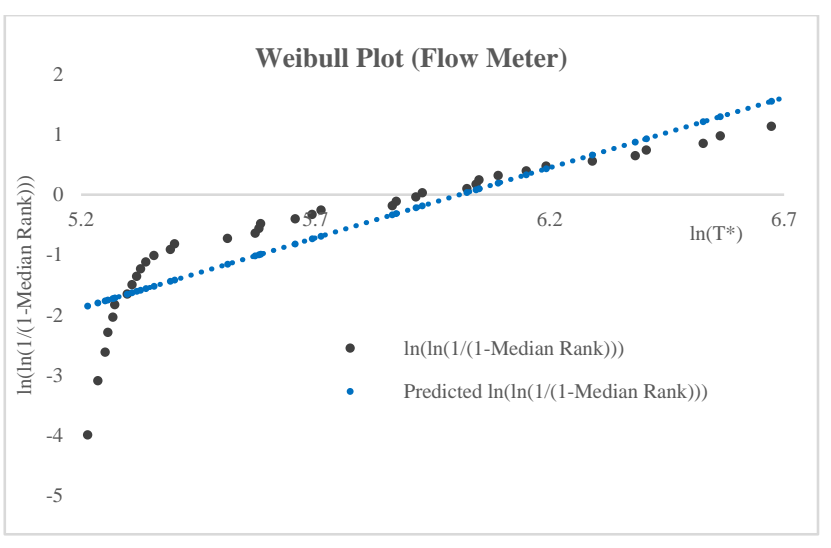

Fig. 2. Weibull Plot for Flow Meter

Regression analysis of defect data was carried out to obtain shape parameter $\beta$. Characteristic life $\alpha$ for the asset group was estimated as follows: 


$$
\alpha=\mathrm{e}^{-\beta}
$$

Probability of Failure (P-F) curve for the asset class was developed as shown in Figure 3. From this curve, time to reach a target reliability of $95 \%$ is extrapolated for desired interval for PM.

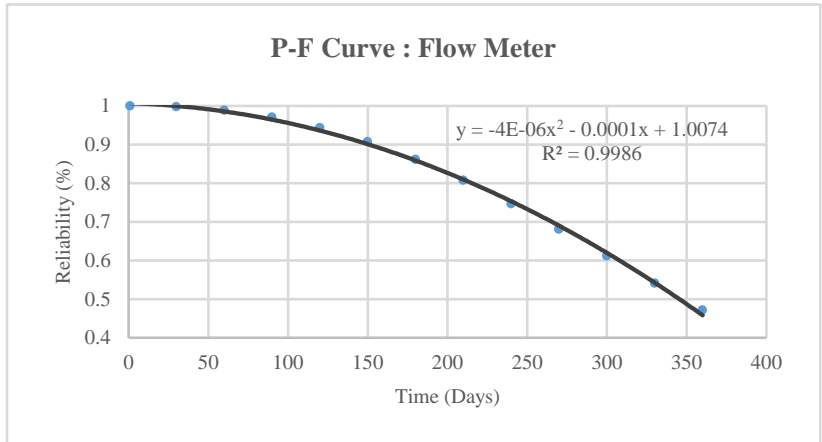

Fig. 3. P-F Curve for Flow Meter

Table 3 provides findings from analysis of 14 classes of assets across four categories. The proposed maintenance frequency is decided based on lowest possible cost considering a minimum threshold of $95 \%$ reliability.

TABLE 3

PROPOSED PM INTERVALS FOR DIFFERENT GROUPS OF ASSET CLASSES

\begin{tabular}{|c|c|c|c|c|}
\hline Group & Asset Class & $\begin{array}{c}\text { Estimated } \\
\text { Threshold } \\
\text { for } 95 \% \\
\text { Reliability } \\
\text { (days) }\end{array}$ & $\begin{array}{l}\text { Existing } \\
\text { Maint. } \\
\text { Frequency }\end{array}$ & $\begin{array}{l}\text { Proposed } \\
\text { Maint. } \\
\text { Frequency }\end{array}$ \\
\hline \multirow{4}{*}{1} & Nutr. Analyser & 75 & $1 \mathrm{~W}$ & $1 \mathrm{M}$ \\
\hline & Flow Switch & 523 & $1 \mathrm{Y}$ & $1 \mathrm{Y}$ \\
\hline & Orthoph. Sensor & 160 & $1 \mathrm{~W}$ & $3 \mathrm{M}$ \\
\hline & Chl Res Anlyser & 184 & $2 \mathrm{~W}, 1 \mathrm{Y}$ & $6 \mathrm{M}, 1 \mathrm{Y}$ \\
\hline \multirow{3}{*}{2} & Diss O2 Anlyser & 214 & $1 \mathrm{M}$ & $6 \mathrm{M}$ \\
\hline & $\mathrm{pH}$ Analyser & 205 & $2 \mathrm{~W}$ & $3 \mathrm{M}$ \\
\hline & UV Int Analyser & 188 & $\begin{array}{l}2 \mathrm{M}, 6 \mathrm{M}, \\
1 \mathrm{Y}\end{array}$ & $6 \mathrm{M}, 1 \mathrm{Y}$ \\
\hline \multirow{4}{*}{3} & Flow Meter & 113 & $1 \mathrm{Y}$ & $6 \mathrm{M}$ \\
\hline & Turb. Analyser & 152 & $1 \mathrm{Y}$ & $1 \mathrm{Y}$ \\
\hline & Solenoid Valve & 269 & $1 \mathrm{Y}$ & $1 \mathrm{Y}$ \\
\hline & Actuator & 232 & $1 \mathrm{Y}$ & $9 \mathrm{M}$ \\
\hline \multirow{3}{*}{4} & $\begin{array}{l}\text { Level Sensing } \\
\text { Element }\end{array}$ & 238 & $1 \mathrm{Y}$ & $1 \mathrm{Y}$ \\
\hline & Lev Ind. Trans. & 185 & $1 \mathrm{Y}$ & $1 \mathrm{Y}$ \\
\hline & Pr. Transmitter & 203 & $1 \mathrm{Y}$ & $1 \mathrm{Y}$ \\
\hline
\end{tabular}

Above analysis provided a basis for rationalisation of PM. For asset classes in Groups 1 and 2, there is a marked reduction in expected maintenance expenditure by extending maintenance intervals.

For Groups 3 and 4, analysis showed a need for increase in frequency for Flow Meters and Level Sensing Elements to provide desired reliability. Although there was a marginal increase of PM cost, the reason behind this is consideration of risks associated with failures along with the fact that more frequent PM picked up early warning signs of potential failure of assets and therefore avoiding high RM costs.
It was recommended for a trial of the new maintenance intervals for a period of 18-24 months, append CMMS data, re-run analysis and fine tune P-F curve to further enhance confidence of decision making in risk based asset management.

In the initial attempts to model failures, $\beta$ obtained from analysis was less than 1 for all asset classes, apparently indicating infant mortality. However, knowing the physical assets have been in service for quite some time without drastic failure events and due to absence of good CMMS data, the analysis was re-run with standard deviation of failure times $\left(\mathrm{T}^{*}\right)$.

Figure 4 shows the actionable defects across the asset classes as on date and are: calibration drift, component failure, decommissioning, wear and material failures. In the subsequent iterations, further analysis on impact of defect data needs to be considered for more accurate decision making of PM intervals.

Defect Distribution

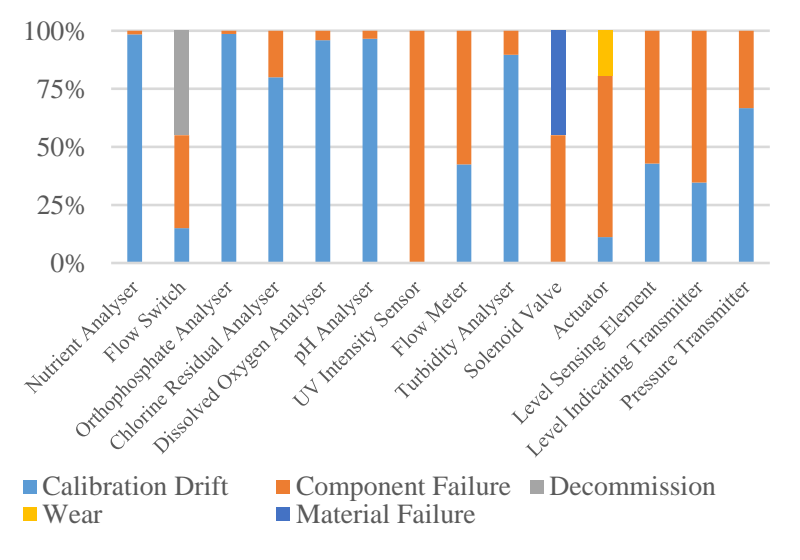

Fig. 4. Distribution of actionable defects

\section{SEWER PRESSURE MAIN}

The Sewer Pressure Main (SPM) consists of 12 pipe line assets with diameters ranging from $375 \mathrm{~mm}$ to $750 \mathrm{~mm}$. Oldest pipe has clocked 41 years in service, most recent sectional replacement was done 6 years ago. Lengths of pipe sections vary from $4 \mathrm{~m}$ to $2.12 \mathrm{~km}$. Material of construction are Ductile Iron-Cement Lined (DICL), Cast iron (CI), Mild Steel-Cement Lined (MS-CL) and Asbestos Cement (AC). There are limited or no maintenance data and failure records for the SPM. Due to operational and budget constraints and challenges of terrain, it was not possible to conduct assessment and gather asset condition data with reasonable level of confidence. However, primary impact of failure is found as operational and business risk followed by costs. The only information available or assets was from the run performed using a freeswimming foam ball with acoustic sensor data, for locating leaks, any gas and air pockets.

During this test, no pipe leaks were identified. There were two major types of findings as shown in Figures 5 and 6 . First one was the location and length of localised air, gas 
pockets and gas slug pockets. The other one was information on pipe wall anomalies. In case of the latter, the location and the qualitative size of the anomaly was identified, however, a differentiation on type of anomaly, i.e wall thinning, crack etc. could not be quantified from the available data. Therefore, this exercise provided a qualitative baseline information of pipeline condition.

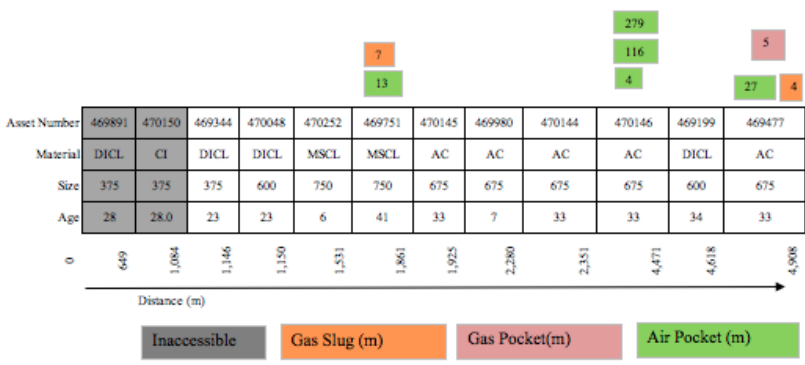

Fig. 5. Location of gas / air pockets

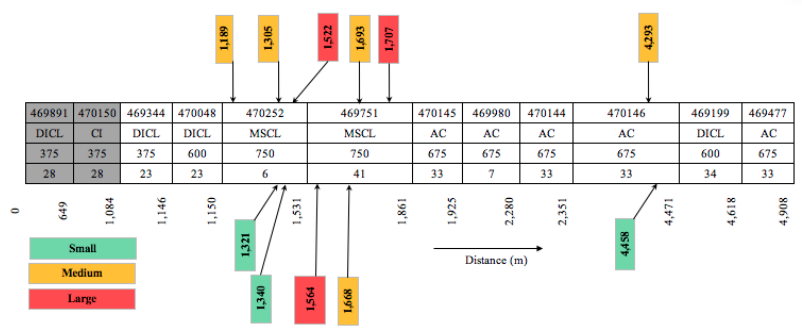

Fig. 6. Distribution of pipe wall thickness anomalies

\section{RESULTS FROM SEWER PRESSURE MAINS}

Table 4 summarizes available limited information on these assets as used for degradation modeling and replacement decisions.

TABLE 4

CURRENT CONDITION OF SPM SYSTEM

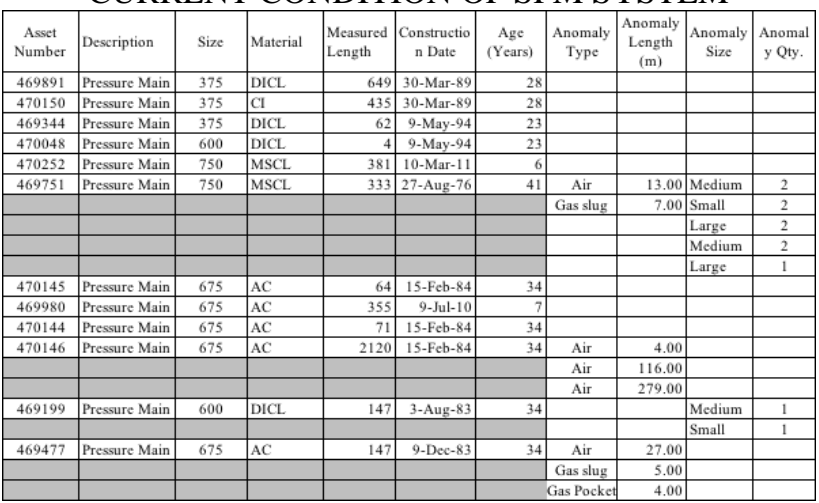

Each asset is assigned a score using a scale of increasing severity from 1 to 5 . Variables considered are age, transport volume and condition. For condition, the scores are derived from the type, length, size and number of anomalies recorded. Current degradation factor is modelled as follows:

$$
\text { Current Degr. Factor }=\exp \left(-\frac{\text { overall score for asset }}{\text { Total Overall Score }}\right)
$$

Overall score is allocated using the product of three individual scores and is presented in Table 5.

TABLE 5

FACTORS USED IN DEGRADATION RANKING OF ASSETS IN SPM

\begin{tabular}{|c|c|c|c|c|c|}
\hline $\begin{array}{c}\text { Asset } \\
\text { Number }\end{array}$ & $\begin{array}{c}\text { Age } \\
\text { Score }\end{array}$ & $\begin{array}{c}\text { Volume } \\
\text { Score }\end{array}$ & $\begin{array}{c}\text { Condition } \\
\text { Score }\end{array}$ & $\begin{array}{c}\text { Overall } \\
\text { Score }\end{array}$ & $\begin{array}{c}\text { Current } \\
\text { Degrad. } \\
\text { Factor }\end{array}$ \\
\hline 470146 & 3 & 5 & 3 & 45 & 0.72 \\
\hline 469751 & 4 & 2 & 4 & 32 & 0.79 \\
\hline 470145 & 3 & 1 & 3 & 9 & 0.94 \\
\hline 470144 & 3 & 1 & 3 & 9 & 0.94 \\
\hline 469199 & 3 & 1 & 3 & 9 & 0.94 \\
\hline 469477 & 3 & 1 & 3 & 9 & 0.94 \\
\hline 470150 & 3 & 1 & 2 & 6 & 0.96 \\
\hline 469980 & 1 & 2 & 3 & 6 & 0.96 \\
\hline 469891 & 3 & 1 & 1 & 3 & 0.98 \\
\hline 469344 & 2 & 1 & 1 & 2 & 0.99 \\
\hline 470048 & 2 & 1 & 1 & 2 & 0.99 \\
\hline 470252 & 1 & 2 & 1 & 2 & 0.99 \\
\hline
\end{tabular}

Relative performance of each asset compared to parametric curve from its current state of degradation till end of expected service life (60 years) is calculated using the relation developed by Park $\mathrm{H}$ et. $\mathrm{Al}$ [6]

$$
S(t)=\exp \left(-\exp (-3.6095 \mu) t^{3.6095}\right.
$$

Failures are modelled for $\mu=5.0647$

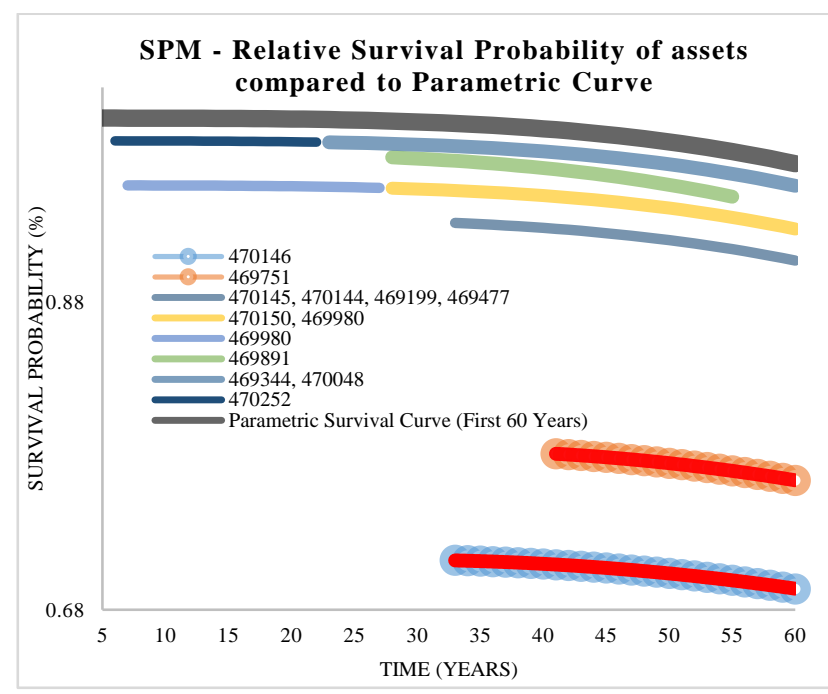

Fig. 7. Relative survival probability of SPM assets

From current condition ranking and relative survival probability using parametric curve (Figure 7), two assets, i.e. 470146 and 469751 were allocated top priority for replacements in a 10 year planning window. The asset replacement cost is estimated accordingly and is provided in Table 6. 
TABLE 6

REPLACEMENT PRIORITY OF SPM ASSETS

\begin{tabular}{|c|c|c|c|c|}
\hline $\begin{array}{c}\text { Asset } \\
\text { Number }\end{array}$ & $\begin{array}{c}\text { Current } \\
\text { Deg. } \\
\text { Factor }\end{array}$ & Priority & $\begin{array}{c}\text { Unit Rate of } \\
\text { replacement } \\
(\$ / \mathrm{m})\end{array}$ & $\begin{array}{c}\text { Asset } \\
\text { Replacement } \\
\text { Cost }(\$, F Y \\
2016-17)\end{array}$ \\
\hline 470146 & 0.72 & $\mathbf{1}$ & 1,200 & $2,544,461$ \\
\hline 469751 & 0.79 & $\mathbf{2}$ & 420 & 139,852 \\
\hline
\end{tabular}

\section{CONCLUSIONS}

In the absence of good quality maintenance data, consideration by the council in the recent past was to rely on OEM recommendations and executive judgements based on experience of maintenance team for maintenance decisions including planning and budgeting. This research has developed risk-based decision models and used pool data to deal with limitations of failure and maintenance history. Through rationalization of PM intervals, primary objective of reducing maintenance costs was achieved. This has significant potential for further enhancing asset performance and utilization of engineering assets. Findings from this pilot study along with information more accurate asset condition, further enhanced risk analysis and improved option engineering helped in enabling informed maintenance decisions including preventive maintenance intervals and level of interventions. Implementation of research findings resulted in reducing asset capability gaps through timely investments of required capital. Further analysis with new and better quality data over a period of time is recommended for calibration of these models in two to three years' time.

\section{ACKNOWLEDGMENT}

The authors would like to acknowledge and thank the Asset Management Unit of Townsville City Council, Australia for providing the opportunity for this research, maintenance data and tacit knowledge. This work was completed as part of the Master in Maintenance and Reliability Engineering Programme at Federation University.

\section{REFERENCES}

[1] NH Kim, D. An., JH Choi, "Introduction. In: Prognostics and Health Management of Engineering Systems". Springer, 2017, pp $1-24$.

[2] JS Zikorska, M. Hodkiewics, and L. Ma, "Prognostic modelling options for remaining useful life estimation by industry". Mechanical Systems and Signal Processing, vol 25, no 5, pp 1803-1836, 2011.

[3] T. Salunke, NI Jamadar, SB Kivade, Prediction of Remaining Useful Life of Mechanical Components - A review, IJESIT, vol 3, no 6, 2014, pp 125-135.

[4] M. Pecht and R. Jaai, A prognostics and health management roadmap for information and electronics-rich systems, Microelectronics Reliability, vol 50, pp 317-323, 2010
[5] J Coble, JW Hines, Applying the general path model to estimation of remaining useful life, IJPHM, vol 2, no 7, pp 1-13, 2011.

[6] H Park, SH Tin and, HD Jeong, Procedural framework for modelling the likelihood of failure of underground pipeline assets, Journal of Pipeline Systems Engineering Practice, vol 7, no 2, 2016

[7] Chattopadhyay G, Kumar S, 'Parameter Estimation for Rail Degradation Model', International Journal of Performability Engineering, Vol. 5, No. 2, 2009, $119-130$.

[8] Chattopadhyay G, Issues and Challenges of Balancing Cost, Performance and Risk in Heavy-Haul Rail Asset Management, IEEE International Conference on Industrial Engineering and Engineering Management (IEEM), 2016, 4 to 7 December 2016, Bali, 521-525.

[9] Beebe R, Predictive Maintenance of Pumps Using Condition Monitoring, ISBN: 9780080514642, Elsevier Science, 2004.

[10] Rahman A, Chattopadhyay G., Optimal service contract policies for outsourcing maintenance service of assets to the service providers, International Journal of Reliability and Applications 8 (2), 183-197, 2007.

[11] Chattopadhyay G., Yun WY, Modeling and analysis of warranty cost for 2D-policies associated with sale of second-hand products, International Journal of Reliability and Applications 7 (1), 71-77.

[12] International Standards Organisation, ISO 13381-1, Condition monitoring and diagnostics of machines -- Prognostics - Part 1: General guidelines, 2015. 